\title{
Alfredo Bryce Echenique ENTRE LO PERIFÉRICO Y LO TRANSNACIONAL
}

\author{
Erwin Snauwaert \\ (KU LEVEN, Campus de Bruselas)
}

\section{Introducción}

Mientras Alfredo Bryce Echenique (Lima, 1939) es generalmente reconocido por su obra de ficción, que comprende cuentos y novelas y en la que destaca Un mundo para Julius [1970], novela que encarriló su aventura literaria, no ocurre igual con sus ensayos. Si no es por unas razones francamente equivocadas, como ocurre con el plagio que se detectó [Araújo Fontalvo, 2014] en buen número de ellos ${ }^{1}$, la crítica solo raras veces les dispensa atención a estos últimos textos. Sin embargo, la producción ensayística del autor limeño, que abarca tanto ensayos propiamente dichos como memorias, artículos o simples crónicas, representa un volumen bastante considerable y, en cuanto a temática, muchas veces puede leerse como complementaria a sus escritos de ficción. Más específicamente, estos textos se reparten sobre las colecciones Crónicas personales [1988] -que contiene el volumen A vuelo de buen cubero [1977], unas primerizas crónicas que versan sobre la estancia del escritor en el sur de los Estados Unidos-, Permiso para vivir [1993], A trancas y barrancas [1996], Crónicas perdidas [2002], Entre la soledad y el amor [2005], Permiso para sentir [2005] y Penúltimos escritos [2009].

Este último libro resulta interesante porque, a pesar de que agrupa 42 textos de temática muy diversa -como ya lo sugiere el subtítulo Retazos de vida y literatura-, incluye unas referencias dispersas pero esenciales para entender ciertos elementos clave del universo literario de Bryce. En efecto, Penúltimos escritos no solo vuelve a tocar aspectos que se elaboran en su obra novelística o

\footnotetext{
${ }^{1}$ Tal como lo señala Breña [2012], se trata de una totalidad de 40 plagios que Bryce principalmente se ha negado a admitir y que causaron unas fuertes polémicas cuando en 2012 se le otorgó el premio de la Feria Internacional del Libro de Guadalajara, México. A este respecto, es conveniente señalar que el presente estudio no se enfocará en esos textos controvertidos.
} 
cuentística -como, para citar solo algunos, las referencias a París incluidas en «Pequeña mitología parisina» [2009: 59] o en «Lejano Mayo del 68» [2009: 89] que remiten al contexto histórico en el que se desarrolla la novela La vida exagerada de Martín Romaña [1981] o los relatos incluidos en Guía triste de París [1999]- sino que también sintetiza unas líneas de fuerza que rigen los otros libros de ensayos. Concretamente, siete crónicas se refieren explícitamente a la naturaleza excéntrica de Latinoamérica y del Perú en particular, un tema que se profundiza en diferentes crónicas anteriores y que en la presente colección se elabora siguiendo dos pistas que finalmente parecen tener una relación íntima entre sí. Si los textos «Madrid», «Dichosos latinos» y «Triste como una playa peruana» insisten en la posición periférica que ocupa América Latina en el mundo, se enfatiza en «Una actitud ante la literatura y el arte», "Crianza y malacrianza literaria», "La idea de Universidad» y «Nuestra literatura en el mundo» la necesidad de que este continente se abra a las influencias exteriores. Así, esta segunda vertiente termina infundiéndoles al Perú y a Latinoamérica en general una vocación transnacional en la que desempeña un rol preponderante la propia actividad literaria.

\section{Lo periférico: Latinoamérica frente al mundo}

La primera serie de textos pone de relieve la posición «excéntrica»-en la acepción más etimológica de la palabra, por la que denota el alejamiento con respecto a los focos de la cultura internacionalque ocupan muchos países latinoamericanos. De este modo, «Madrid» se concentra en la fascinación que tenía Ernest Hemingway por la capital española y que hasta le incitó a rebautizarla como «La Capital del Mundo» [2009: 53]. A pesar del esplendor que le atribuye el escritor norteamericano a dicha ciudad, se describe también cómo esta, en la segunda mitad del siglo XX, se veía «fea, chiquita, bastante pueblón; pobre, toscota y tascota, con mucha grasa en la comida [...]» [2009: 55] en comparación con París, donde residía en aquella época el propio Bryce. Al mismo tiempo, el autor alega que, por más que, como erudito latinoamericano, dispusiera de un equipaje cultural que rebasaba ampliamente el de los madrileños, no podía quitarse de encima una sensación incómoda. También en una ciudad que no admitía comparación con París se sentía aquejado por «esa condición de deudor precario que nos acompleja y caracteriza a los latinoamericanos ante la Madre Patria y la Sabia Europa» [2009: 53], que parece arraigar en un tipo de complejo de inferioridad cultural ante las hegemonías intelectuales europea y estadounidense. 


\subsection{Un complejo de inferioridad cultural}

En la crónica «Dichosos latinos» el autor lexicaliza este fenómeno apuntando que : «Nuestro [=de los latinoamericanos] mestizaje carga también un grave complejo de inferioridad, de bastardía social» [2009: 99]. Más precisamente, ve esta falta de postura y de autoconfianza como consecuencia de un sempiterno descontento inherente a la mentalidad latinoamericana, que contrasta con la generosidad que sus vecinos norteamericanos manifiestan desde siempre en la celebración de Thanksgiving day.

\footnotetext{
O sea que es falso aquello de que [los norteamericanos] hagan acción de gracias porque son ricos, ya que no siempre lo fueron. Tal vez sea todo lo contrario [...] son ricos porque supieron dar las gracias cuando tenían el vaso lleno a medias, mientras que nosotros, los dichosos latinos, los pobres parientes del sur, andamos como andamos porque nos hemos pasado media vida quejándonos de que a nuestro vaso le faltara por lo menos una cuarta parte para estar del todo Ileno [2009: 98].
}

Esta ausencia de realismo y de sentido común para encontrar un equilibrio existencial y social hace que los latinoamericanos se quejen «mientras bailamos», como sucede, por ejemplo, en el tango y los convierte en «parientes muy pobres de un pasado de incas y de virreyes [...] de un mundo hecho añicos» [2009: 99]. Este desconcierto se exterioriza en la crónica «Triste como una playa peruana» a través del aspecto pelado que tiene la zona costera peruana. Bryce se vale a este respecto de las experiencias de Herman Melville, quien sitúa parte de la acción de su cuento Benito Cereno [1855] en esas costas desiertas y en su famosísima novela Moby Dick [1851] reproduce la atmósfera desoladora de Lima, cogida en la garúa. Un mismo desamparo se desprende, según Bryce, de algunos textos de Romain Gary, en los que la descripción del Perú respira un mismo ambiente mortífero.

[...] otro gran escritor, el francés Romain Gary, siente también una oscura y extraña fascinación por nuestras costas y playas, en una magnífica novela titulada nada menos que Los pájaros van a morir al Perú. Y qué hombre de nuestras costas no ha visto una y mil veces el negro espectáculo de unos alcatraces, de unos pelícanos o de unos gallinazos que agonizan, indiferentes cual fantasmas a nuestra desasosegada presencia [2009: 162]

La constatación de que «de los mares y playas de este mundo las de Perú se llevan la palma en lo que a fealdad y tristeza se refiere» [2009: 161] se sintoniza con la idea de inferioridad cultural ya presentada, que, a punto de repetirse, parece haberse convertido en un tema recurrente en la 
ensayística de Bryce. En efecto, si tomamos por caso A trancas y barrancas [1996], se alude a una misma sensación en el texto «Historia peruana de la capital del mundo», cuyo título otra vez remite a la percepción de Hemingway.

[...] resulta que los latinoamericanos de carabela y madrepatria somos españoles sin España y europeos sin Europa, de la misma manera en que, por ejemplo, un argentino es un uruguayo que ha vivido en París, un uruguayo es un argentino con complejo de inferioridad y jamás será lo mismo un desnudo griego que un calato peruano, o sea, en pelotas física y económicamente. Entonces nos leemos Europa entera para llegar a ser adultos a tiempo completo [...] [1996: 53-54].

Además, estas últimas palabras resaltan que, al negarse los latinoamericanos a hacerse adultos, su sentimiento de inferioridad tiene que ver con una suerte de persistencia de la infancia. Esta vinculación a la niñez no solo recuerda el libro de Luis Alberto Sánchez El Perú: nuevo retrato de un país adolescente [1985], que elabora la inmadurez socio-económica y cultural de la que padece la sociedad peruana, sino que también se cristaliza en unos personajes novelescos [Snauwaert, 1998: 98-101]. Este es el caso de Martín, el protagonista del díptico Cuaderno de navegación en un sillón Voltaire ${ }^{2}$ que, durante su exilio voluntario en París -ciudad en la que quiere hacerse escritor al ejemplo de los grandes representantes del boom-, combina el respeto por los valores literarios tradicionales que defiende su madre con el apego a su terruño peruano. Esta condición, que podríamos calificar de «edípica» ${ }^{3}$, se concreta en unas escenas en las que el héroe vuelve mentalmente a la niñez y se ve a sí mismo «[perdiendo] edad y estatura» o «chiquitito y deforme» [Bryce, 1981: 469] y antes que nada lo margina de la vida parisiense. Rebasando los límites del solo ensayo para perfilarse también en las novelas y los cuentos del autor, este alejamiento psíquico, que se manifiesta en los planos individual y social, agranda su alcance. Además, por este aspecto transgenérico, el supuesto complejo de inferioridad «refuerza la denuncia de [unos] estereotipos» [Snauwaert, 2016: 180], que se formulan desde el extranjero y hasta en el seno de la sociedad latinoamericana misma.

\footnotetext{
${ }^{2}$ Este díptico se compone de las novelas La vida exagerada de Martín Romaña [1981] y El hombre que hablaba de Octavia de Cádiz [1985] que a continuación mencionaremos por separado.

${ }^{3}$ Esta tendencia edípica no se tematiza exclusivamente en este libro, sino que también se manifiesta, por ejemplo, en Un mundo para Julius [1970], la primera novela del autor en la que se enfoca a la aristocracia limeña desde una perspectiva infantil, o en La última mudanza de Felipe Carillo [1988] que infunde en el protagonista homónimo un mismo complejo y lo pormenoriza parodiando el análisis psicoanalítico como tal.
} 


\subsection{Unos estereotipos bidireccionales}

Efectivamente, la marginación comentada se materializa en unas visiones estereotipadas que van en dos sentidos: desde Europa y desde la propia América Latina. En cuanto a la primera dirección, Bryce presenta el papel insignificante que desempeña el Perú actualmente en el orden mundial en contraste con la resonancia mítica que sigue teniendo en Europa. Así, en la crónica «Madrid» narra cómo los dueños de un hotel en la ciudad homónima terminan por aceptar la condición humilde y el aspecto descuidado de sus huéspedes peruanos porque «son así de feos porque son incas» [2009: 54]. Tales alusiones intempestivas al carácter enigmático del Perú o a unas etapas espectaculares de su pasado también se leen en "Un piropo para Amália», un texto integrado en Permiso para sentir [2005] en el que Bryce narra cómo sus colegas de una universidad parisina siguen identificándole con el imperio incaico o con otras facetas arquetípicas de la historia latinoamericana. A este respecto, vuelven a mencionarse los mitos y el exotismo inducidos por la Europa renacentista o las sempiternas revoluciones, a través de unas alusiones a los innumerables movimientos guerrilleros o al carisma de Ernesto «Che» Guevara.

\footnotetext{
Yo venía $[\ldots]$ de un país en vías de desarrollo llamado Perú. Un país lejano [...], mítico e incaico, riquísimo, El Dorado, y al mismo tiempo sede de la fuente de la Eterna Juventud y Tierra Prometida y Territorio de las Amazonas [...] cuando era joven lector de español de la Universidad de Nanterre $[\ldots]$ tenía entre las chicas de mis cursos [...] un éxito que, por no calificar de «cheguevaresco» o "guerrilleresco» [...] tan de moda por aquellos años pero que yo no practicaba porque era escritor y [...] calificaré de "éxito amazona", tan sólo para darles una idea de lo exótico que me veían mis lindas alumnas parisinas [...] [2005: 165-166].
}

Más específicamente este pasaje muestra cómo "Latinoamérica pasa indebidamente por un mundo imaginario europeo que la reinventa a su guisa, exagerando lo pintoresco y agudizando por lo mismo las diferencias culturales" [Snauwaert, 2012: 297].

Esta incomprensión entre Latinoamérica y el Perú en particular con el resto del mundo no se deriva solo de una mentalidad europea propensa a la generalización y al arquetipo sino que, según Bryce, igualmente procede de unas expectativas desajustadas que piensa reconocer en sus compatriotas cuando estos se acercan a la realidad europea. La posición subalterna que ocupa Madrid frente a la capital francesa señalada ya anteriormente se explica a partir de la admiración desproporcionada que tienen los latinoamericanos por París. Así presenta las «rebeliones, emancipaciones y transgresiones 
que $[\ldots .$.$] en Lima [\ldots]$ se habían llevado a cabo a principios del siglo XX» como unas realizaciones que solo podían darse «copiando con complejo de deudor precario el París del XIX» [2009: 55]. Esta idea de París como encarnación del Siglo de las Luces y de Francia como país siempre más avanzado tiende nuevamente el puente entre Penúltimos escritos y los otros libros de ensayos. Más particularmente, reanuda con «el mito del buen salvaje al revés», un clisé formulado desde la misma Latinoamérica, que el autor ya destacó en «El mercado del lugar común», un texto incluido en su primera colección Crónicas personales [1988].

\footnotetext{
Este profesor, que en Francia se Ilama Legrand o Durand, y que [...] te corrige tus errores al hablar, alcanza en América Latina una aureola mágica, un irresistible poder de seducción, capaz de conservar en alcohol los más antiguos sueños de aquellas damotas que, sin la Alianza Francesa, morirían de aburrimiento y soledad. Mi amigo, el profesor francés [...] me explicó sabiamente aquel problema [...] en pocas palabras: «Es el mito invertido. Es el mito del buen salvaje al revés» [1988: 184].
}

Tanto esta exageración de los méritos de Francia, patente en la irradiación que se le atribuye, por ejemplo, a la lengua francesa -la autoridad del colega que corrige las faltas de francés, el prestigio de la Alianza francesa- por la que los «resultan [...] ser víctimas de sus sueños» [Snauwaert, 2012: 300], como la sensación de pertenecer a un país desprestigiado cuadran con el complejo de inferioridad esbozado más arriba y comunican una visión de América Latina propiamente errónea. En palabras de Julio Ortega se asiste pues al fenómeno de «lo que pasa por mundanidad popular puede ser estereotipo; y peor, aún, prejuicio, cuya licencia es una suerte de "agujero negro" del lenguaje» [2012: 129]. En efecto, se establece una imagen del continente que, por más que se aparte de la realidad, se impone cada vez más convirtiéndose en una suerte de profecía que se cumple a sí misma. Esto lo explicita Bryce en «El cóndor sigue pasando», otra crónica recogida en Permiso para sentir [2005].

\footnotetext{
Una enorme falsificación -que ha continuado hasta nuestros días- empezaba a ponerse en marcha, en lo que a América Latina corresponde. Y por más que en la universidad yo me mataba explicándoles a mis colegas y alumnos que en el caso peruano, por ejemplo, se estaba prefabricando lo andino precisamente en un momento en que la división entre el Perú criollo y el Perú andino empezaba a borrarse, ellos me miraban como un aguafiestas llegado a París con el único fin de asesinar al más hermoso de todos los cóndores [2005: 136-137].
} 
Tal concepción inadaptada muestra hasta qué punto los sueños que nutren tanto los latinoamericanos como los europeos distan de la realidad objetiva. Precisamente esta representación ilusoria contribuye a mover a los diferentes países de América Latina hacia la periferia y a presentarlos por tanto como entidades «excéntricas», diferentes de lo común, en el escenario mundial.

\section{Lo transnacional: la literatura como apertura al mundo}

Sin embargo, al mismo tiempo que enfatiza el carácter periférico del Perú, Bryce Echenique insinúa que tal marginación no significa que se deba menospreciar a su patria. Esta ambivalencia se cuela en la crónica ya citada "Triste como una playa peruana», en la que señala que, a pesar del aspecto desgarbado de su entorno, "los peruanos somos como las ballenas: nos alejamos muchísimo de nuestro país pero retornamos siempre a él» [2009: 163]. Esta actitud que incitó al propio Bryce a exiliarse voluntariamente a París con el objetivo de convertirse en escritor para, después de una odisea por Europa, finalmente volver al Perú 4 es reforzada al final del artículo por las palabras de Guillaume Apollinaire: «hay que viajar muy lejos, pero, eso sí, amando siempre nuestro hogar» [2009: 163]. Esta cita da a conocer una ambigüedad que se profundiza en otros ensayos de Penúltimos escritos y que toma cuerpo en un eclecticismo que determina la posición existencial y orienta la práctica literaria del autor.

\subsection{El eclecticismo como estrategia literaria}

Efectivamente, en «Crianza y malacrianza literaria» Bryce da cuenta de que sus posiciones literarias no solo fueron influenciadas por los clásicos franceses y «Manzoni, Goldoni, Pirandello, Goethe, Cicerón y Plutarco, Milton, Leopardi, Montherlant» [2009: 64] -lecturas que efectuaba por insistencia de su preceptora en Lima- o por el existencialismo que estaba en boga cuando llegó a Francia, sino sobre todo por sus estudios de derecho. Durante esta carrera sus profesores consiguieron enseñarle que no se debía rechazar ninguna escuela jurídica para aprender algo de cada una de ellas. Esto lleva al autor a afirmar que

Fruto de tal cantidad de posiciones [...] a París llegué [...] convertido en una persona terriblemente dispuesta al eclecticismo. Y éste ha sido uno de mis rasgos de diversidad psicológico más peruano

\footnotetext{
${ }^{4}$ Bryce emigró a París en 1964 y residió también en Alemania, Grecia, Italia y España, para cambiar nuevamente Europa por Lima en el año 2010.
} 
o más constante o no sé qué, pero lo cierto es que yo me siento totalmente peruano al adoptar una posición ecléctica en todos los asuntos de esta vida y obra [2009: 65].

Indicando que esta postura intelectual «le calzaba como un guante a mis pies de futbolista infantil y juvenil» [2009: 65] conecta con una imagen que ya elaboró en varios ensayos anteriores. Así, en la contribución «En España está surgiendo un racismo extraño», incluida en Crónicas perdidas, precisa que «[...] en los partidos de fútbol jugaba un tiempo con cada uno de los dos equipos en liza, para saber qué sentían los dos» [2002: 124]. A continuación vuelve a motivar esta decisión en el presente ensayo presentándose como un jugador que

[...] optó, siempre que no se lo impidieron falsas razones patrioteras o de exagerada rivalidad deportiva, por jugar el primer tiempo en un equipo y el segundo en el otro, al que por lo demás uno ve tan de cerca en el campo que resulta de lo más natural quererle echar una manito, ¿no, manito?, y Ilegarlo a ver y sentir como un álter ego [2009: 65-66].

Esta imagen resulta tan pertinente para su vocación literaria que vuelve a repetirla tal cual en «La idea de Universidad» insistiendo en que la escritura le permitió «practicar esa alternancia de la que [...] surgen la ironía y el humor» [2009: 132$]^{5}$.

\subsection{Hacia una literatura transnacional}

Reanudando con estos dos conceptos vitales para la elaboración literaria, este eclecticismo parece constituir una disposición fundamental que rige el fuero interior del artista y que Bryce en el ensayo «Una actitud ante la literatura y el arte» denomina «empatía».

\footnotetext{
Esta cualidad [...] consiste en otorgarle una emoción a la causa externa que la estimula, y puede resultar esencial para una exitosa labor de creación literaria, ya que empuja al escritor a identificarse con el ángel y con el demonio, con la víctima y con el verdugo, es decir con aquellos personajes de su obra que más admira y que más detesta. Con ello le dará vida a sus libros, con ellos romperá con la pobreza de todo maniqueísmo [...] [2009: 47].
}

Este maniqueísmo no solo le pone unas trabas a la escritura en general sino que se opone a la actitud de Bryce, quien puede inspirarse de diferentes modelos literarios al mismo tiempo. Como lo comenta en «Crianza y malacrianza literaria», vino a París con el objetivo de hacerse escritor,

\footnotetext{
${ }^{5}$ La pertinencia literaria de este eclecticismo también se ilustra en el ya mencionado ensayo «En España está surgiendo un racismo extraño» en el que Bryce confiesa que, al no poder ponerlo en la práctica durante un partido con el equipo juvenil del Perú ante Argentina «tomé la decisión de dejar el fútbol y dedicarme a la literatura, donde sí es posible la ironía y la política» [2002: 124].
} 
pertrechado del equipaje cultural inculcado por Mercedes Tola, su preceptora limeña, que consistía sobre todo en «profundos repasos del XVII francés». Paradójicamente, también «lleg[ó] [...] para descubrir la literatura latinoamericana contemporánea» [2009: 64] al juntarse de nuevo en esta misma ciudad con su exprofesor Mario Vargas Llosa y otros escritores como Julio Ramón Ribeyro y Julio Cortázar. Estos lo familiarizaron tanto con el existencialismo francés de Sartre y sobre todo de Camus -este último «dudaba, lo cual ya era francamente maravilloso en un mundo de grandes certidumbres y definiciones», por lo que se acercaba en lo posible al perfil del «ecléctico en el sentido peruano de la palabra» [2009: 77]- como con la incipiente explosión de la novela latinoamericana. Además, por su interés por la literatura canonizada y por su conciencia de la elevada calidad artística contenida en la obra de los iconos del boom, una generación a la que él mismo se vinculó íntimamente y que consolidó la idea de una literatura latinoamericana como entidad supranacional identificadora, Bryce supo reconocer la superchería de unos imitantes que, por diletantismo o mala fe, atentaron contra sus propios ideales literarios.

\footnotetext{
Aquellos muchachos que, en bares y cantinas, en hembritas e izquierdismo de turno, iban a labrarse un porvenir glorioso, aquellos que iban «a escribir una novela compadre que tenga algo de Cortázar, de Fuentes [...] y muchísimo éxito mío», eran realmente dignos de la mayor atención y yo la puse y gané horas y horas perdidas hasta llegar a la conclusión de que [...] el daño que iba a producir en ellos el boom estaba profundamente vinculado a nuestra inmadurez y subdesarrollo [2009: 82-83].
}

Aludiendo a la inmadurez y al subdesarrollo, esta cita vuelve a sacar a colación el aspecto periférico de América Latina y, más particularmente, lo ve como perjudicial para la evolución literaria que empezaba a perfilarse en su seno. A estas alturas, estos supuestos escritores que solo tratan de lucirse aprovechándose del izquierdismo que estaba de moda en Europa en los años posteriores a la Revolución cubana, recuerdan nada menos que la trama de La vida exagerada de Martín Romaña [1981]. En esta novela, Bryce le endosa a su protagonista las propias dificultades que experimentó como escritor en ciernes durante la revolución estudiantil parisina de mayo del 68: Martín es obligado por su mujer Inés, una incondicional militante izquierdista, a abandonar su ideal literario proustiano. Para complacer a un grupo de presuntos marxistas a la que ella pertenece, el héroe tiene que sustituir a su ídolo por una literatura de compromiso, escribiendo un libro sobre sindicatos pesqueros peruanos de los que no sabe nada. La estafa intelectual que significa tal práctica literaria queda clara 
cuando al final del libro Inés así como los miembros de su cenáculo terminan por abandonar la militancia política respectivamente por una vida lujosa en Brasil y por unos puestos bien pagados en diferentes ministerios peruanos. Sin embargo, después de una fuerte depresión, Martín seguirá con su propio proyecto literario cuando se enamore de otra chica, una relación que forma el tema de una continuación de la novela, El hombre que hablaba de Octavia de Cádiz [1985].

Es muy significativo que en La vida exagerada de Martín Romaña el protagonista, debido al control permanente que ejerce sobre él su mujer se vea a sí mismo empequeñecido y que interprete «la mínima expresión a al que me hallaba reducido» como una posición desde la cual «se puede observar tan bien la vida» [Bryce Echenique 1981: 257]. En consecuencia, la predisposición a considerarse a sí mismos como ciudadanos de segunda categoría típica en los latinoamericanos acaba constituyendo un prisma a través del cual se puede considerar el mundo de forma más perspicaz. Igual que sucede en otras colecciones de ensayos como Crónicas personales [1985] o A trancas y barrancas [1996], también en Penúltimos escritos Bryce no se limita a señalar las taras de las que sufre América Latina sino que también las utiliza para resaltar los defectos de otras naciones. Así en «Dichosos latinos», después de haber elogiado a España alegando que «nos legó el Derecho Romano, el mundo judeocristiano y la civilización occidental» señala que «nadie blasfem[a] tanto y mejor que un español» [2009: 98]. Esta observación podría interpretarse como anodina si no revelara una rudeza cada vez más creciente que tiende a alejar a este país de un espíritu de colectivismo y convivialidad que solía tener en común con otras regiones latinas ${ }^{6}$.

Rechazando el aprovechamiento gratuito de unos temas izquierdistas y hasta indigenistas ${ }^{7}$ y contraatacando con mucho criterio a las naciones que tradicionalmente se consideran superiores, Bryce indica que la suerte de la literatura latinoamericana no reside en el mero interés por lo regional sino que, al contrario, depende de su relación con el mundo occidental. Esta intensa afiliación a la tradición literaria de Occidente, que ya se vislumbraba para Bryce en la herencia cultural que le legó su preceptora, brevemente se tematiza en «Nuestra literatura en el mundo». En este ensayo, después de haber examinado la problemática de la traducción de sus obras, el autor concluye que «pocos son [...] los escritores cuya obra logra una difusión más allá del mundo occidental» [2009: 137].

\footnotetext{
${ }^{6}$ Esta diferencia intercultural se profundiza en los libros Crónicas personales [1988] y A trancas y barrancas [1996] respectivamente en los ensayos «¿Por qué siempre regreso a España?» y «La ternura de los españoles»-texto en el que Bryce por primera vez afirma que «el blasfemar continuo de los españoles $[. .$.$] arrincona y hasta aterroriza a los latinoamericanos»$ [1996: 290]- en los que se ejemplifica cómo «los españoles evolucionaron a finales del siglo XX de un espíritu colectivista que compartían con los peruanos hacia un individualismo en el que prevalecen los intereses personales sobre los contactos humanos» [Snauwaert, 2016: 178].

7 Refiriéndonos otra vez al ejemplo de La vida exagerada de Martín Romaña, podríamos alegar que la novela que Inés le manda escribir a Martín se vincula con el indigenismo ya que, en realidad, es como si esta redacción pretendiera finalizar el proyecto literario inacabado que José María Arguedas emprendió en El zorro de arriba y el zorro de abajo [1971] y que tematiza precisamente la problemática social de los pescadores en Chimbote.
} 
Si bien estas palabras hacen constar la escasa resonancia que tienen las letras latinoamericanas en otras partes del orbe, de todos modos valorizan su conectividad con las letras europeas o norteamericanas. De esta forma, evidencian «las relaciones que entabla la producción literaria con la globalización» [Jay, 2010: 5] y participan de lo que Jay llama «the transnational turn», «el giro transnacional» [2010: 2]. Aparte de ocasionar una dilatación espacial, tal perspectiva también incide en el nivel espiritual estableciendo un «distanciamiento como elemento necesario de la creación artística» [2009: 45], que Bryce, siguiendo a Flaubert, defiende en «Una actitud ante la literatura y el arte». Esta distancia le permite al artista fijarse en «las posibilidades estéticas aprovechables» [2009: 47], por lo que la literatura no está pendiente de la mera presencia de unas realidades locales, sino que da acceso a un universo más abarcador cuya construcción se basa en una pericia técnica cada vez más pronunciada.

[...] sólo esas técnicas les [= a los escritores] permiten dar la impresión de que [el arte] está reproduciendo genuinamente la experiencia infinitamente renovable de una vida. Y [...] en el sentido de que el artista recurre cada día más a más técnicas novedosas, pienso que sólo a través de una serie de «trampas y estafas» logra darnos la impresión de haber disecado la vida toda en un libro [2009: 46].

En este sentido, la atención por el refinamiento formal finalmente contribuye a lo que Ramiro Esteban Zó define como la «internacionalización de la literatura hispanoamericana» [2011: 205] y tiene como consecuencia que los ensayos comentados, a pesar de su aspecto bastante fragmentario, sirven la causa de la transnacionalización de la cultura latinoamericana. Como lo observa también Pascale Casanova, este abandono de una posición puramente nacional, que bautiza «dénationalisation», corre parejas con «L'émancipation littéraire» [1999: 133] que hace que las letras en América Latina en adelante ya no dependan de unos intereses ajenos.

\footnotetext{
Si les [...] intellectuels nationaux se référaient à une idée politique du littéraire afin de constituer un particularisme national, les nouveaux venus vont se référer aux lois littéraires internationales et autonomes pour faire exister nationalement un autre type de littérature et de capital littéraire [Casanova, 1999: 451-452]
}

\footnotetext{
${ }^{8}$ La traducción es nuestra. El original reza: «the relationship of literary production to globalization» [Jay, 2010: 5]
} 
Enfatizando la importancia de la técnica y desviando el enfoque cultural de lo regional a lo transnacional, Bryce nos enseña cómo la literatura de América Latina puede transcender el sentimiento de inferioridad que generalmente frena su desenvolvimiento socio-cultural. Al atenerse a estos preceptos literarios, este continente se injerta una capacidad crítica que le permite abandonar su papel de segundón y medirse con otras naciones occidentales. Conforme a esta vocación transnacional, las letras latinoamericanas cumplen con los requisitos de una «literatura transatlántica» que Julio Ortega define como «el intento de reconstruir la plaza pública de los idiomas comunes, desde la perspectiva de un humanismo internacional y a partir del modelo de la mezcla, que sigue siendo el principio moderno por excelencia» [2012a: 67]. Al desinteresarse de las preocupaciones regionalistas, tales como estas se declaran a través de unos estereotipos que relegan a América Latina a la periferia, para fijarse en la proyección transnacional de estos diferentes países, Bryce opta por «una textualidad más articulatoria y más dialógica» [Ortega, 2012b: 10]. Esta apertura al mundo les da a las letras peruanas y latinoamericanas en general un alcance mucho más vasto que en el pasado y, por tanto, les permite ocupar una posición más céntrica en el ámbito socio-cultural internacional.

\section{Conclusión}

En resumen, los ensayos comentados se fundan en una paradoja entre lo periférico y lo transnacional. Primero, los textos «Madrid», «Dichosos latinos» y «Triste como una playa peruana» ponen de relieve un complejo de inferioridad y unos estereotipos provenientes tanto de Europa como de los propios países de América Latina. Estos aspectos tienden a presentar a Latinoamérica como una sociedad inmadura e incapaz de tomar en manos su propio destino, una interpretación que se ve corroborada también en buen número de crónicas que preceden Penúltimos escritos. Sin embargo, los artículos «Una actitud ante la literatura y el arte», «Crianza y malacrianza literaria», «La idea de Universidad» y «Nuestra literatura en el mundo» infunden en esta colección de ensayos un movimiento en sentido contrario. Más específicamente, el aspecto periférico antes que nada constituye una finta ya que la posición excéntrica que le reserva al Perú y, por extensión, a Latinoamérica en general, en realidad Ilama la atención en la necesidad de conectarse con el mundo occidental y fomenta así un ensanchamiento espiritual que potencia a la propia literatura latinoamericana. Realizando esta ambición transnacional, a través de una pronunciada tecnicidad narrativa y de la 
creación de una conciencia cultural más pronunciada, la literatura se presenta en estos ensayos de Bryce como el discurso emancipador de Latinoamérica por excelencia.

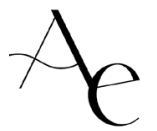

\section{BIBLIOGRAFÍA}

ARAÚJO FONTALVO, Orlando: «Bryce Echenique: un mundo para el plagio», Resonancias, 2014. http://www.resonancias.org/content/read/325/bryce-echenique-un-mundo-para-el-plagio-pororlando-araujo-fontalvo. Fecha de consulta: 28/12/2017.

BREÑA, Roberto: «Bryce Echenique: de plagios y premios», El País, 2012.

https://elpais.com/cultura/2012/11/13/actualidad/1352833928_446496.html. Fecha de consulta: 04/01/2018.

BRYCE ECHENIQUE, Alfredo: La vida exagerada de Martín Romaña. Barcelona: Argos Vergara, 1981.

— Crónicas Personales. Barcelona: Anagrama, 1985.

_- A Trancas y barrancas. Madrid: Espasa Calpe, 1996.

— Crónicas Perdidas. Barcelona: Anagrama, 2002.

—_, Permiso para sentir. Barcelona: Anagrama, 2005.

—_, Penúltimos escritos. Lima: Peisa, 2009.

CASANOVA, Pascale: La république mondiale des lettres. Paris: Seuil, 1999.

JAY, Paul: Global matters: the transnational turn in literary studies. Ithaca: Cornell University Press, 2010.

ORTEGA, Julio: «El algoritmo barroco. Literatura atlántica y crítica del lenguaje», Revista de la Universidad de México. UNAM., 104 (2012b), pp. 58-67. http://www.revistadelauniversidad.unam.mx/ojs_rum/files/journals/1/articles/96/public/96683-1-PB.pdf. Fecha de consulta 29/12/2017.

—_, «Prólogo», en Julio Ortega (ed.), Nuevos hispanismos. Para una crítica del lenguaje dominante. Madrid/ Fráncfort del Meno: Iberoamericana/Vervuert. 2012a, 9-16.

SNAUWAERT, Erwin: Crónica de una escritura inocente: la focalización implícita como base interpretativa de las novelas de Alfredo Bryce Echenique. Leuven: Leuven university press, 1998. 
—_, «Entre distancia y participación. El estereotipo de la diferencia entre América Latina y Europa en la obra de Alfredo Bryce Echenique», en Nadia Lie, Silvana Mandolessi y Dagmar Vandebosch (eds.), El juego con los estereotipos. La redefinición de la identidad hispánica en la literatura y el cine postnacionales, Brussels: Peter Lang, 2012, 293-302.

—_, «El indigenismo como obstáculo a la transnacionalización en el ensayo peruano contemporáneo», Foro Hispánico, 56 (2016), pp. 172-185.

ZÓ, Ramiro Esteban. «La obra de Alfredo Bryce Echenique desde la óptica de las redes intelectualesliterarias», Cuadernos del CILHA 12 (2011), pp. 202-208. 